\title{
El cultivo de piña en el municipio de Ticuantepe: Situación actual y perspectivas
}

Silvia Elena Rose ${ }^{1}$

1 Maestría en Administración y Dirección de Empresas (MADE) Facultad de Ciencias Económicas y Empresariales de la UCA. Apdo. 69, Managua, Nicaragua.

Recibido: abril 2006 / Aceptado: mayo 2006

LA PIÑA ES UN PRODUCTO CUYA DEMANDA INTERNACIONAL se incrementa anualmente.

Nicaragua cuenta con clima y suelos adecuados para su producción. Además, en el municipio de Ticuantepe cercano a la capital, hay una importante tradición piñera. Sin embargo, la piña que se cultiva no tiene demanda internacional y la que sí tiene demanda internacional, se cultiva en extensiones mínimas. Aunque el producto es prometedor, los productores no tienen apoyo institucional, no están organizados y no cuentan con infraestructura. Este trabajo explora los obstáculos que enfrenta el sector y plantea alternativas de solución.

Palabras clave: piña-cultivo-investigaciones-Nicaragua, oferta y demanda

\section{Introducción}

Nicaragua cuenta con grandes extensiones de tierra cultivable; por lo tanto, su principal actividad económica es la agricultura. Durante muchos años, los denominados productos tradicionales de exportación (café, algodón, azúcar, carne) garantizaron la estabilidad económica del país pero la caída de sus precios internacionales ha obligado a modificar las estrategias. Desde los 90, se desarrollan iniciativas para fomentar la producción y exportación de productos agrícolas no tradicionales. Entre ellos, la piña.

La piña fresca es muy cotizada en el mercado internacional por su alto valor nutritivo. En muchos países, se cultiva a gran escala y con alta tecnología, incluso donde no tienen el material vegetativo ni el clima adecuado.

\section{Alcance de este estudio}

Este trabajo pretende analizar el desarrollo del cultivo de la piña en el municipio de Ticuantepe. El estudio se realizó mediante entrevistas personales con 10 productores 
de piña de las comarcas La Francia, La Borgoña y Cebadilla, para analizar tres niveles de problemas: en la base productiva; en el acceso al mercado; e incentivos. Asimismo, para proponer estrategias para el diseño e implementación de un plan que desarrolle el sistema productivo e incremente en la rentabilidad.

Para validar la información recogida, se visitaron instituciones relacionadas con el cultivo: Instituto Nicaragüense de Tecnología Agropecuaria (INTA), CENADE, Ministerio de Agricultura y Ganadería (MAG), Centro de Exportaciones e Inversiones (CEI), Comisión Nacional de Exportaciones, Asociación de Productores y Exportadores No tradicionales (APPEN), casas comerciales y agencias aduaneras.

Por último, se analizaron los impactos de los diferentes problemas sobre los costos de producción. Para agrupar los problemas se utilizó el marco conceptual del análisis FODA que muestra un diagnóstico claro de la situación actual de los productores de piña del municipio de Ticuantepe.

\section{El cultivo de la piña en Nicaragua}

La piña (Ananas comosus) se cultiva en Nicaragua desde tiempos precolombinos. Se consume fresca; en conservas, jaleas, vinos, licores, vinagres, alcohol, jugos y helados. Hay muchas variedades, siendo las más conocidas Cayena Lisa, Española, Queen, Cabezona y Montufar de rodaja dulce.

La variedad más sembrada en Nicaragua es Monte Lirio, sobre todo para consumo interno donde se consume como fruta fresca y en mermeladas, pero no gusta en el mercado internacional. Su eje central es grueso, lo que dificulta su industrialización. El 90\% de la producción mundial corresponde a la variedad Cayena Lisa, de gran demanda en Estados Unidos y la Unión Europea. Sin embargo, esta variedad, rica en azúcares y eje central delgado, casi no se produce en Nicaragua.

\section{La piña en Ticuantepe}

El cultivo de la piña se introdujo en municipio de Ticuantepe en 1965, donde ha ido desplazando a los cultivos tradicionales. Actualmente, es el mayor productor de piña del país. Se ubica a $18 \mathrm{~km}$. al sureste de Managua. Tiene aproximadamente $68 \mathrm{~km}^{2}$, en su mayor parte, de áreas boscosas y pequeñas lomas. La producción agrícola está en manos de pequeños y medianos productores, organizados en cooperativas, colectivos de trabajo, o individuales que suelen agruparse para la compra de insumos y compartir costos de transporte para la comercialización de sus productos, alquileres de tierra, etc.

En Ticuantepe hay unos 800 productores, con un área sembrada de unas 2,500 manzanas ${ }^{1}$. De este total, unas 20 manzanas corresponden a la variedad Cayena Lisa, para un $0.8 \%$ del total, que no es suficiente para ofertar volumen y calidad constantes al mercado internacional. La variedad se introdujo a Nicaragua desde Costa Rica para siembras comerciales en 1990, por el proyecto CEE-ALA 86/30, pero según algunos productores y técnicos entrevistados, el producto no era de buena calidad. 


\section{Costos del cultivo de piña variedad Monte Lirio}

Las entrevistas manifiestan que los costos de producción varían mucho, quizá por deficiente control de los costos o por manejos inapropiados en los cultivos, aunque el promedio por manzana es de 24,912.19 córdobas, y por docena, 11.96 córdobas. La mano de obra representa el 25\% del total; los insumos, el 39\%; y el material de siembra, el 36\%. Datos técnicos del INTA $^{2}$ señalan que los costos de producción de una manzana ascienden a 22,296.54 córdobas de los que el 16\%, mano de obra; 30\%, insumos; y 54\%, material de siembra.

Este material son los hijos de la planta. Los de buena calidad cuestan 0.40 córdobas c/u, pero los productores consiguen hijos hasta por 0.20 córdobas, aunque de mala calidad y hasta regalados. En los estándares de producción por manzana, hay también variabilidad: mientras algunos siembran 20,000 plantas/manzana para un rendimiento de 18,000 piñas/ año (90\%), otros siembran 30,000 plantas por manzana para 25,000 piñas/año (83\%). El INTA señala que la cantidad de plantas/manzana depende del terreno y del sistema de siembra utilizado. Sin embargo, lo más frecuente en la zona es 30,000/plantas/manzana, independientemente del tipo de suelo y sistema de siembra.

\section{Costos del cultivo de piña, variedad Cayena Lisa}

Según las entrevistas, los costos de material de siembra son más altos en esta variedad: 0.60-0.80 córdobas/hijo; los costos de preparación, mantenimiento y cosecha se incrementan en un 40-50\% respecto a la variedad Monte Lirio. Los rendimientos por manzana de variedad Cayena Lisa se incrementan hasta el 95\% . Esta variedad casi no se cultiva en Nicaragua pues no tiene demanda nacional. Por ello, los márgenes de utilidad son los que se obtendrían en el mercado internacional. Así se demuestra que, a pesar del aumento en los costos, la exportación sí genera utilidades: el margen de utilidad por caja exportada es de 1.785dólares ${ }^{4}$, lo cual hace atractivo el mercado internacional de la piña.

\section{Base Productiva}

Materia Prima.- La piña se propaga mediante hijos o vástagos. La variedad Monte Lirio produce en cada cosecha de 5 a 8; la Cayena Lisa, produce 2 o 3 hijos por planta.

Insumos y Materiales.- Se utilizan agroquímicos para una producción homogénea, pero sus precios limitan el acceso. Los productores recurren a fórmulas de su creación que, a la larga, dañan las plantas. Hay exoneraciones arancelarias a la importación de los agroquímicos necesarios, pero no son suficientes.

Tecnología.- La piña se adapta a diferentes manejos tecnológicos y se puede planificar la cosecha, pero las posibilidades de las variedades locales no se han investigado. Las plantaciones se manejan de manera empírica y se desconfía de la asistencia técnica. Además, en los tiempos de abundancia, el precio cae hasta en un 80\%. El mayor problema radica en que los productores no cuentan con equipo de transporte para comercializar sus cosechas, porque no pueden adquirirlos, con lo que se aumentan los costos de comercialización en el $58.53 \%$; con su propio transporte, el costo se vería reducido en un 50\%.

Financiamiento.-Los productores de piña del municipio de Ticuantepe no son considerados sujetos de crédito porque no tienen garantías solidarias de respaldo, el mercado nacional 
no garantiza un precio estable y los intereses para el sector agrícola son muy elevados. Las ONGs que promueven la producción de piña, tienen tasas de interés tan elevadas que no atraen a los usuarios del crédito.

Por otra parte, los productores no están organizados. En 1981 se formó la Organización de Productores de Ticuantepe, con ocho cooperativas, integradas por unos 400 socios y 1,500 manzanas sembradas de variedad Monte Lirio. Aunque se construyó un centro de acopio y se iniciaron contactos para exportar a Europa, los problemas de la época hicieron fracasar este intento. Este antecedente exitoso hace que los productores permanezcan interesados en organizarse para lograr mayor participación en la cadena de comercialización en el mercado nacional y penetrar en el internacional. La falta de organización tiene como consecuencia el poco poder para la negociación y la gestión; falta de esquema empresarial y de respaldo para acceder a financiamiento; poca participación en la cadena de comercialización y en el precio final, lo que incide en las utilidades.

\section{Comercio local de piña}

El principal centro de acopio de piña es los mercados de Managua, especialmente el de Mayoreo, donde se concentra aproximadamente un 90\% de la producción de piña. Los mayoristas controlan la distribución, toman las decisiones de venta, alejando al productor del detallista y del consumidor final. El resto se comercializa mediante transportistas que compran el producto en las plantaciones, para llevarlo a Costa Rica y El Salvador. Se calcula que la participación del productor es del 19.35\% en períodos de abundancia, llegando el período de escasez al 44.44\%.

\section{Acceso al mercado}

\section{Infraestructura}

Caminos: Aunque Ticuantepe tiene una amplia red de carreteras pavimentadas, los caminos a las plantaciones son malos y se vuelven intransitables en la temporada de lluvias, lo que aumenta los costos de comercialización en un 19.5\%.

Puertos marítimos: Los puertos de Nicaragua no reúnen condiciones para la exportación y son caros. Por ello, los exportadores utilizan Puerto Limón o Puerto Cortés.

Infraestructura de acopio: Escasean bodegas de almacenamiento para tener un control del mercado, lo que afecta a los productores.

Producto sin valor agregado industrial: En la zona hay una planta agroindustrial instalada que no funciona. Si se añade valor agregado al producto, se evita lo perecedero y se estabilizan los precios.

\section{Servicios}

El productor no tiene información del mercado nacional e internacional, por lo que vende su producción al mejor postor. De cara al mercado internacional, no conoce los precios, ni los países productores, exportadores e importadores, ni las normas de calidad internacional, trámites internos de exportación, etc.

Diferentes instituciones pretenden apoyar a los productores, pero son muy burocráticas 
y lentas: CEI, APPEN. El productor siente que estas instituciones incrementan sus costos porque para lograr atención, hay que realizar dos o tres visitas ${ }^{5}$; se cobra la consulta a los centros de documentación: CEI, C\$15.00 y APPEN cobra C\$ 5.00 por consulta; y cobran por unas capacitaciones demasiado técnicas y que no hablan de los problemas que interesan a los productores.

\section{Incentivos al sector productor de piña}

Exenciones fiscales.- La carga fiscal no impacta en los costos de producción de piña, pues las unidades económicas son tan pequeñas que quedan fuera del alcance de los impuestos; el sector agrícola está exento de impuestos indirectos para fomentar su desarrollo; hay exención total del IR a todas las cooperativas legalmente constituidas que se dediquen a cualquier actividad económica, pero sólo a los excedentes de sus funciones propias como cooperativas; durante los dos primeros años desde su constitución, las cooperativas agropecuarias y agroindustriales están exentas del IBI; exención de IGV a las Cooperativas Agropecuarias, Industriales y de Transporte en compras locales o importaciones de maquinaria y equipo; exoneración total de aranceles a la importación (ATP, DAI) a la importación de materias primas, bienes intermedios y bienes de capital e insumos necesarios para sus actividades.

Apoyo a las exportaciones.- El Decreto de Promoción de Exportaciones No. 37-91 señala los siguientes beneficios: Exoneración de los impuestos y derechos que gravan las importaciones de maquinarias necesarias para la producción, repuestos, materia primas, artículos semielaborados, insumos y material de empaque de los productos que hayan de exportarse; exoneración de IGV para compras de insumos o materias primas nacionales para producir los bienes exportables; acceso a divisas generadas con la exportación para emplearlas en el pago de importaciones; desde el 1 de enero de 1998 se establece una tasa de reintegro tributario de 1.5\% del valor FOB de las exportaciones, pero sólo al exportador; eliminación de pago por permisos o licencias de exportación; reintegro del IGV pagado por las compras de materiales utilizados para el proceso de exportación.

\section{Apoyo Institucional}

Aduanas.- Actualmente no hay exportaciones, por lo que no fue posible conocer el comportamiento de esta institución.

Trámites de Exportación.- Para simplificar los trámites, se decretó la creación del Centro de Trámites de Exportaciones (CETREX), adscrito a la Comisión Nacional de Promoción de Exportaciones, que es un avance pero se puede simplificar la documentación requerida; el trámite del permiso fitosanitario, extendido por el Ministerio de Agricultura y Ganadería, es lento y, a veces, es cobrado; la compra del Formato Único de Exportación encarece la exportación, pero es indispensable presentar el comprobante de su cancelación para obtener el permiso Fitosanitario del MAG. Pero los incentivos a las exportaciones no se dan solamente mediante leyes sino también mediante reglas y procedimientos claros y eficientes. 


\section{Mercado internacional de piña: oportunidades para Nicaragua}

La producción mundial de piña se ha incrementado en un 16.37\% de 1990 a 1997, pasando de un volumen de 11 millones de toneladas métricas en 1990 a 13 millones en 1997. Tailandia es el mayor productor con un 16.62\% del total; Filipinas con un 10.30\%; Brasil con 9.67\%. Costa Rica, Honduras y Guatemala, países centroamericanos, juntos representan un 2.31\% del total mundial.

En cuanto a la piña fresca, en el período 1990-1996, el mercado mundial se incrementó en casi un 30\%, pasando de 596 mil toneladas métricas en 1990 a 774 mil toneladas métricas en 1996. El mercado europeo es uno de los más fuertes a nivel mundial. En el mercado de Estados Unidos el cultivo de la piña se desarrolla en Hawai, Florida, California y Puerto Rico, que abastecen un 50\% del mercado local ${ }^{6}$. Sin embargo, los Estados Unidos son importadores netos de piña fresca y se encuentran entre los principales del mundo, con un volumen en 1996 de 135 mil toneladas métricas, equivalente al 18.6\% del total mundial. El $44 \%$ de las importaciones totales de piña fresca proceden de Costa Rica y Honduras.

El mercado de Estados Unidos es una oportunidad de exportación, por los hábitos de consumo de los norteamericanos. Pero es un mercado exigente en cuanto a calidad y apariencia de la fruta.

\section{Precio internacional de piña fresca}

Después de analizar el mercado internacional, la pregunta es si Nicaragua tiene oportunidad para exportar y la respuesta es que sí, porque: hay un mercado internacional en expansión; en el tratado de libre comercio firmado con México, la piña está en la categoría de productos que serán desgravados en cinco años; hay una ventana de comercialización en el mercado de Estados Unidos, por la tendencia creciente de sus importaciones, por la procedencia de sus importaciones, y la distancia entre ambos países que constituye una ventaja comparativa; en el marco del Mercado Común Centroamericano, la región, incluyendo a Nicaragua, podría constituirse en un poder de negociación en el ámbito internacional como la región con mayores exportaciones mundiales de piña fresca. 


\begin{tabular}{|c|c|}
\hline Fortalezas & Oportunidades \\
\hline 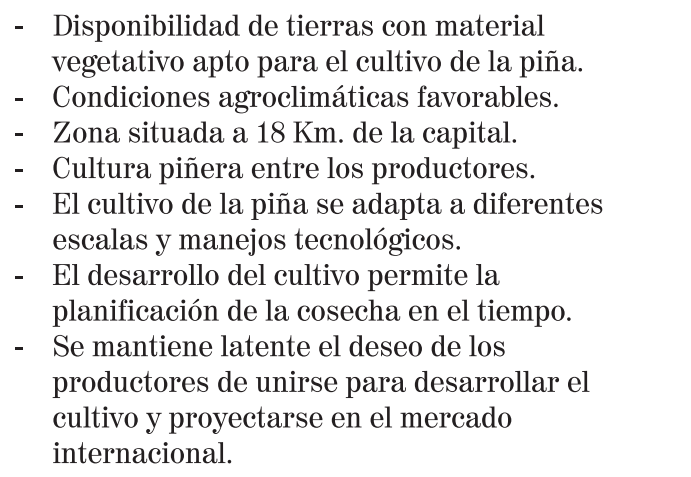 & $\begin{array}{l}\text { - Red de carreteras en buenas condiciones. } \\
\text { - Se goza de algunos incentivos tanto para el } \\
\text { desarrollo del sector agrícola como para el } \\
\text { fomento de las exportaciones de productos no } \\
\text { tradicionales. } \\
\text { - Incentivos a las Cooperativas. } \\
\text { - Planta Agroindustrial instalada en la zona. } \\
\text { - Mercado Internacional de la piña en expansión. } \\
\text { - La oportunidad de pertenecer a una región que } \\
\text { en conjunto es la mayor exportadora de piña al } \\
\text { nivel mundial. } \\
\text { - Oportunidades generadas como país integrante } \\
\text { del Mercado Común Centroamericano. }\end{array}$ \\
\hline Debilidades & Amenazas \\
\hline $\begin{array}{l}\text { - Alta variabilidad de en los costos de producción } \\
\text { entre un productor y otro. } \\
\text { - Rentabilidad negativa de los productores de } \\
\text { piña. } \\
\text { - Ausencia de planificación de la producción lo } \\
\text { que genera alta variabilidad de las cosechas. } \\
\text { - Prácticas agroquímicas inadecuadas } \\
\text { ocasionando grandes problemas fitosanitarios } \\
\text { que disminuyen los rendimientos por manzana. } \\
\text { - Nulo valor agregado industrial del producto. } \\
\text { - Ausencia de recursos por parte de los } \\
\text { productores para invertir en: } \\
\text { - Tecnología de producción y } \\
\quad \text { comercialización. } \\
\text { - Maquinaria y equipo de siembra. } \\
\text { - Equipo de Transporte. } \\
\text { - Bodegas de Almacenamiento. } \\
\text { - Baja incidencia de la capacitación técnica. } \\
\text { - Ausencia de un esquema empresarial por parte } \\
\text { de los productores y de las organizaciones. } \\
\text { - Ausencia de un sistema contable y de control de } \\
\text { costos. } \\
\text { - Bajo poder de negociación y gestión de los } \\
\text { productores. } \\
\text { - Baja participación de los productores en la } \\
\text { cadena de comercialización. } \\
\text { - Ausencia de participación en el mercado } \\
\text { internacional. }\end{array}$ & $\begin{array}{l}\text { - Ausencia de variedades de cultivos de } \\
\text { exportación. } \\
\text { - Ausencia de inversiones en: } \\
\text { - Investigación y Desarrollo. } \\
\text { - Validación de tecnología. } \\
\text { - Capacitación del capital humano. } \\
\text { - Infraestructuras: Caminos, servicios } \\
\text { públicos (agua, energía, comunicaciones), } \\
\text { puertos marítimos. } \\
\text { - Infraestructura Agroindustrial. } \\
\text { - No hay acceso a financiamiento. } \\
\text { - Alta variabilidad de los precios. } \\
\text { - Deficiencia en lo que respecta a reglas y } \\
\text { procedimientos en: } \\
\text { - Servicios de Aduana. } \\
\text { - Trámites de Exportación } \\
\text { - Trámite de permiso Fitosanitario. } \\
\text { - Deficiente red de servicios de información } \\
\text { acerca de: } \\
\text { - El comportamiento del mercado } \\
\text { internacional de la piña. } \\
\text { - Precios internacionales. } \\
\text { - Compradores o Brokers. } \\
\text { - Normas internacionales de calidad. } \\
\text { Todo este tipo de información existe pero no } \\
\text { llega al productor con facilidad. } \\
\text { - Capacitaciones por parte de las instituciones } \\
\text { de apoyo fuera de la realidad de los } \\
\text { productores. }\end{array}$ \\
\hline
\end{tabular}




\section{Elementos estratégicos para el desarrollo del cultivo}

El municipio de Ticuantepe presenta ventajas competitivas favorables al desarrollo del cultivo de la piña. El diagnóstico del estudio, utilizando el marco conceptual del análisis FODA, revela la situación que enfrentan los productores de piña:

Este diagnóstico indica claramente por qué no se ha desarrollado un proceso inversionista en el sector, obstaculizando el crecimiento del producto; si no se toman decisiones para resolver los cuellos de botella a la inversión, el cultivo de la piña puede desaparecer en Nicaragua. Si los obstáculos o amenazas se solucionaran, se convertirían en oportunidades para estimular la inversión, aprovechar las fortalezas y superar las debilidades del sector piñero.

\section{Propuesta de un plan estratégico de desarrollo}

El siguiente plan estratégico se desarrolla en tres fases: a) fortalecimiento de la base productiva y asentamiento de las bases para la exportación e incrementar la participación en la cadena de comercialización local del producto; b) aumento al máximo de las utilidades defendiendo la participación en el mercado nacional e internacional; y c) cuando el producto podría comenzar su etapa de declinación, se propone la estrategia para darle continuidad al ciclo.

Para iniciar la primera etapa, es indispensable solucionar los problemas. Por eso, la primera fase se detalla con más precisión. En la segunda fase, sólo se indica la estrategia para mantener los objetivos alcanzados en la primera y algunas consideraciones que deben tomarse en cuenta. En la última fase, se indica la estrategia para dar continuidad al proceso. Todo ello para lograr el desarrollo sostenido del cultivo de la piña en el municipio de Ticuantepe mediante la reconversión integral del sistema productivo y el incremento en la rentabilidad.

\section{Fortalecimiento de la base productiva}

En la primera etapa se busca fortalecer la base productiva y organizacional, incrementar el control en la cadena de comercialización local y regional y lograr la máxima participación en el mercado internacional. Para ello, es necesario desarrollar ordenadamente el área de organización y de producción.

En el primer paso, los productores deberán organizarse en cooperativas, bajo un esquema empresarial, para aprovechar los beneficios derivados de la Ley de Cooperativas. Este paso demandará transformaciones empresariales en dos niveles: el gerencial en cada unidad productiva; y el gremial, donde se generen estrategias conjuntas para lograr los objetivos.

En el área de producción, se trata de obtener el máximo rendimiento y calidad en la variedad para consumo nacional y en la de exportación, utilizando los recursos de la manera más eficiente, mediante el necesario financiamiento para capital de trabajo, de manera que se puedan aprovechar fluida y oportunamente las posibilidades de producción y las oportunidades de los mercados. 
En esta área, habrá que tomar decisiones sobre: importación de material de siembra; renovación de las plantaciones de la variedad Cayena Lisa; aumento del área sembrada con variedad Cayena Lisa para garantizar el abastecimiento en el mercado internacional; mejorar los rendimientos de la variedad Monte Lirio; los procedimientos de producción se deben realizar de acuerdo a las técnicas establecidas en cuanto a la selección, preparación del terreno y siembra de hijos, prácticas agroquímicas, planificación de la inducción floral, cosecha y manejo post-cosecha; desarrollo de nuevas variedades de cultivos de exportación; capacitación de los productores en producción, organización empresaria y normas de calidad, enviándolos a países productores o mediante apoyo institucional.

En el ámbito de las inversiones, se exige un proceso riguroso de inversiones en tres niveles estratégicos:

Inversiones e Infraestructura Pública y Servicios: Dotar el área con caminos y carreteras; agua, energía eléctrica y comunicaciones en las plantaciones; e inversión en investigación y desarrollo, validación de tecnología, etc.

Inversiones en las fincas: Renovar las plantaciones de Cayena Lisa e incrementar el área sembrada de dicha variedad. Dados los bajos niveles de capital y de ingresos de los actuales productores, el crecimiento de las inversiones en las fincas debería beneficiarse de transferencias parciales.

Inversiones al nivel de las organizaciones: equipo de transporte para comercializar el producto; maquinaria para la siembra, mantenimiento y cosecha de la piña; tecnología para producción y comercialización; capacitación de los productores; importación de material de siembra con calidad de exportación; inversiones en equipo de comunicación que es de vital importancia para la exportación; inversión en infraestructura de acopio o bodega de almacenamiento.

En la primera etapa, los resultados financieros deberán pasar de los actuales márgenes negativos a márgenes de rentabilidad positivos. Este es el objetivo de esta etapa que se logrará mediante riguroso control de los costos y obtención de los mejores precios en el mercado nacional e internacional.

En esta etapa, la estrategia de mercadotecnia consiste en aumentar al máximo la participación en la cadena de comercialización local y la participación en el mercado internacional. La base de esta estrategia está en el cumplimiento en cuanto a volúmenes, fechas de entrega y normas de calidad.

Para aumentar la participación en la cadena de comercialización local hay dos estrategias: llegar al detallista o al consumidor final mediante el establecimiento de puestos en los mercados, que es donde se concentra el mayor volumen de comercialización del producto; y la generación de una flota de vehículos y un centro de acopio para vender el producto a los mayoristas en los mercados o directamente en las bodegas de almacenamiento.

Las bodegas de almacenamiento se deben construir en esta etapa para facilitar la comercialización local e internacional. La presentación de la fruta deberá garantizarse de acuerdo con las normas internacionales de calidad, para lo cual es conveniente organizar un centro de acopio y clasificación. Las exportaciones deberán iniciarse en el mercado 
de Estados Unidos por las oportunidades que presenta este mercado y por los márgenes utilidad resultantes del proceso.

\section{Servicios de apoyo e incentivos}

Si se realizan las necesarias y suficientes inversiones, mejorarán las condiciones de la zona. Pero además serán necesarios cambios en el entorno para facilitar al productor los medios para mejorar su producción y facilitar su acceso al mercado. Estas condiciones son: servicios financieros que faciliten acceso oportuno al dinero para capital de trabajo, y para inversiones a largo plazo; agilización de los procedimientos y trámites por parte de las instituciones de apoyo: trámites de exportación, de aduana, de permisos fitosanitarios, etc.; eficiencia en las instituciones de apoyo y promoción a las exportaciones para prestar sus servicios; incentivos y cargas fiscales que favorezcan la competitividad del producto en el mercado.

\section{Segunda Fase}

La primera etapa trata de resolver todas las debilidades del sector y penetrar en el mercado internacional. El segundo paso busca fortalecer y mantener ese mercado en el que se entrará a competir con otros países exportadores. La meta será aumentar al máximo las utilidades defendiendo la participación en el mercado. La estrategia consistirá en diversificar las variedades para diferentes usos como fruta fresca y para industrialización.

Las inversiones en Investigación y Desarrollo deben mantenerse para desarrollar nuevas variedades de acuerdo a las tendencias de los gustos y preferencias de los mercados, además de invertir en otros aspectos necesarios para el buen funcionamiento del proceso.

Por otro lado, es recomendable que las organizaciones de productores mantengan un riguroso control de costos para ser competitivos en el mercado internacional y vigilar los cambios en el mercado internacional, nuevas variedades, precios internacionales y sus tendencias, descubrimientos de nuevos nichos de mercado, etc.

\section{Tercera Fase}

En este nivel, se podría pasar a otra etapa que consistiría en iniciar el proceso de industrialización de la piña para consumo nacional e internacional, pues la piña se consume como fruta fresca, pero también en conservas, jugos, vinos, etc.

Puesto que hay una planta agroindustrial instalada en la zona, que no ha iniciado operaciones por todos los problemas analizados, ésta es la oportunidad para dar continuidad al desarrollo del sector.

Naturalmente, deberán realizarse inversiones en tecnología, infraestructura, investigación y desarrollo, investigaciones de mercados internacionales, etc. Por último, diseñar la estrategia de penetración de los nuevos mercados. 


\section{Notas}

1 INTA, Ticuantepe

2 Guía Tecnológica para la Producción de Piña. SEE/ALA 86/30

3 Perfil del cultivo de la Piña, FNI

4 Los datos del costo de comercialización fueron obtenidos mediante consultas y entrevistas a las entidades correspondientes.

5 Validado por entrevista personal

6 Perfil de Mercado de la Piña, CEl.

\section{Referencias bibliográficas}

-MEMBREÑO, Benito, INTA, entrevista realizada el 15 Junio de 1998

-OROZCO, Emilio, CENADE, entrevista realizada el 15 de Junio de 1998.

Perfil de Mercado de la Piña, CEI.

-SEE/ALA 86/30, Guía Tecnológica para la Producción de Piña 